\title{
ANTHROPOMETRIC DATA FOR DEVELOPING INDUSTRIAL STANDARDS IN APPAREL MANUFACTURING FOR THE HOME MARKET
}

\author{
Ermira Shehi, Tatjana Spahiu, Genti Guxho \\ Textile and Fashion Department, UPT, Tirana, Albania \\ e-mail: Ermira.shehi@upt-tekstilmoda.org; Tatjana.spahiu@upt-tekstilmoda.org; Genti.guxho@upt-tekstilmoda.org
}

\begin{abstract}
:
Standard measurements identifying body measurements are very important in apparel manufacturing because they help in identifying different sizes, economize the material, and decide on production quantities according the needs. Despite this, the industry has not accepted any one particular system for garment sizing so far. It is a wellknown fact that the production companies and merchandisers use their own sizing system as a marketing tool convincing customers of the advantages over other products available in the market. Despite the sizing system used, all the systems are based on the myth that humans have a body with proportional measurements. At the same time, the changes in life styles, nutrition and ethnic composition of populations lead to changes in the distribution of body dimensions (e.g., the obesity epidemic), and require regular updating of anthropometric data collections. Regarding the consumption of the garment products in Albania, there are about 840 garment companies mainly working for the foreign market. Only $2 \%$ of them produce for the home market, in a low percentage of their total production. The number of companies aiming to enter into the full package of production is increasing considerably, even those registering their brand name for the Albanian market. We can find examples of garment and shoes production companies going for the full cycle production for the home market in Tirana, Fier, Berat, Kavaja, and Shkoder. The industrial full cycle production for the home market requires anthropometric measurements and setting up the sartorial system. There is no sizing system in Albania that the producers can refer to. The industrial standard helps manufacturers to improve mass-produced garment and reduce cost of production.
\end{abstract}

\section{Keywords:}

Sizing, body measurements, correlation, figure types.

\section{Introduction}

Albania is a country with a long tradition in textile and garment production industry. Textile and clothing sector is $6 \%$ of the manufacturing industry in Albania. The garment industry is one of the leading industries in Albania in terms of people employed and ranks fourth place after the food, the wood/ furniture and the metallurgic industry. Market balance is, however, negative with most of the garments being imported. The high presence of imported garments and shoes can partially be explained by the lack of home production for the home market and partially by the consumer preference for imported products and mainly by the uncertainty of production companies to enter the Albanian market with their products and brand names.

Generally, the body measurements for Albanian population are based on very old studies completed years ago. The sizing system is not updated and not compatible with the variety of measurements nowadays.

For the industrial garment production to be effective, it is necessary to group the measurements. Referring to the fact that body measurements and sizing is based on a study conducted about 30 years ago, problems have been noticed in fitting the garments to the consumer body.
The actual sizing system is too far from being updated with the Albanian population changes. This is an actual problem especially while designing and manufacturing school uniforms, work uniforms for different companies in the field of transport, city services, health system, banks, etc.

\section{Problem formulation}

The case study focuses on two main objectives: (1) to demonstrate the methodology of developing the industrial sizing system for mass production; (2) to demonstrate how the classification of figure types can be done.

\section{Method and procedure}

Overall 203 females have been measured, all employees of a bank in Tirana. Work uniforms are to be produced for them. As known already, it is impossible to design and produce customsized uniforms for every one---because of the required time and cost---we are going to use the concepts of the industrial garment production. The group of workers is similar to a large group of consumers, with similar tastes, but are different from each other, i.e. from the body measurements. The measurements might be similar, exactly the same or different. 
In order that the industrial garment production is effective and useful, the consumer/employees grouping should be done.

For this case study, Tirana is chosen for a number of reasons: (i) buying force is mainly concentrated in Tirana, (ii) Tirana is a relatively good representative of the whole country, due to the migration (during the last 20 years Tirana increased from 200,000 to approximately 700,000 inhabitants since people from all over the country have migrated to Tirana) and (iii) cost.

From the industrial production point of view and consumer needs for personal use, the optimization of the measurement standard is an achievement of maximal level for meeting the consumer needs and preferences, using the minimal possible number of measurement combinations. In this case the anthropometric measurements represent a summary of standards.

For creating two or more measurement standards, we start from the distribution law of measurements frequency. For creating the sizing typology and thus the sizing system, we proceed as follows:

Phase 1. We select the primary measurements of the body. This analysis served for reducing the number of anthropometric variables.

Phase 2. Detect the relationships among variables.

Phase 3. Based on the results of Phase 1 and 2, categories were specified based on the primary measurement (Body height).

Phase 4. These categories were further subdivided on the basis of the second primary measurement (Bust girth) to more precisely classify the body/figure types.

Phase 5. Based on the results of Phase 4, the new body measurement standards are developed according to the body type.

The primary measurements meet the following requirements:

1. The absolute value is higher or approximate with the largest of the whole body measurements.

2. Every measurement has a strong relation only with the measurements at the same level or on parallel levels. In industrial garment production practice, we are limited to the use of two primary measurements (body height and bust girth). At the same time, the correlation between the main measurements should be weak.

As revealed by the studies and literature, among the body measurements exists statistical correlation called normal correlation. This makes possible to reduce the number of the primary measurements, since a number of body measurements could be represented by one primary measurement.

The bust girth and body height meet the above listed requirements. The correlation coefficient between the two primary measurements is low, but their correlation with the other measurements is very strong.

Besides these two primary measurements, the waist and hip girths are very important.

Body measurements have been manually measured and collected. *2. They are:

Head girth, neck girth, chest girth, bust girth, under bust girth, waist girth, hip girth, thigh breadth, knee length, bust depth, wrist length, sitting height, hand length, hand breadth, popliteal length, total body height, inside leg length, arm length, hand length, foot length and weight.

\section{Results}

\section{Figure identification for industrial sizing}

The largest group of females in the study is 20-30 years old with 76 persons; the second largest group is 30-40 years old with 69 persons; the third group is $30-40$ years old with 45 persons; 10 persons are $40-50$ years old and only two are over 60 years.

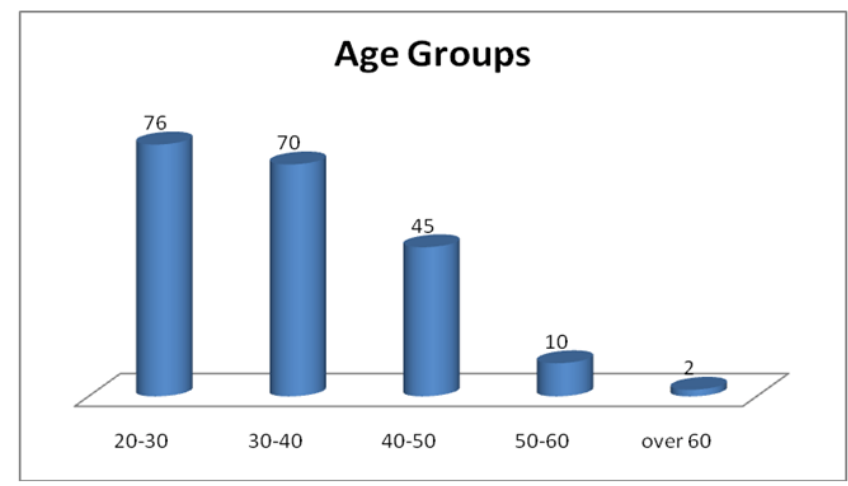

Figure 1. Distribution of females basing on the age.

The body height is identified by the following letters according to the ISO standard.

SH (Short): $\quad 160 \mathrm{~cm}(156 \mathrm{~cm}-163 \mathrm{~cm})$

$\mathrm{N}$ (Normal): $168 \mathrm{~cm}(164 \mathrm{~cm}-171 \mathrm{~cm})$

GJ (Tall): $\quad 176 \mathrm{~cm}(172 \mathrm{~cm}-179 \mathrm{~cm})$

For the sample considered under study the body height and their frequencies are presented:

Table 1. The body height and its frequency for females under 'Short' category.

\begin{tabular}{|c|c|c|c|c|c|c|c|c|c|c|c|c|c|c|}
\hline The body height & 150 & 151 & 152 & 153 & 154 & 155 & 156 & 157 & 158 & 159 & 160 & 161 & 162 & 163 \\
\hline Frequency & 3 & 1 & 1 & 0 & 0 & 4 & 2 & 2 & 12 & 6 & 27 & 4 & 18 & 16 \\
\hline
\end{tabular}


Table 2. The body height and its frequency for females under 'Normal' category.

\begin{tabular}{|c|c|c|c|c|c|c|c|c|}
\hline The body height & 164 & 165 & 166 & 167 & 168 & 169 & 170 & 171 \\
\hline Frequency & 19 & 30 & 8 & 7 & 13 & 0 & 10 & 4 \\
\hline
\end{tabular}

Table 3. The body height and its frequency for females under 'Tall' category.

\begin{tabular}{|c|c|c|c|c|c|c|c|c|c|c|}
\hline The body height & 172 & 174 & 176 & 178 & 180 & 182 & 184 & 186 & 188 & 190 \\
\hline Frequency & 6 & 5 & 3 & 0 & 0 & 0 & 0 & 1 & 0 & 1 \\
\hline
\end{tabular}

Table 4. Correlations between Body Height; Head Girth; II Neck Girth; II Bust Girth; Waist Girth; Hip Girth.

\begin{tabular}{|c|c|c|c|c|c|}
\hline & Body Height & Head Girth & II Neck Girth & II Bust Girth & Waist Girth \\
\hline Head Girth & $\begin{array}{l}0,220 \\
0,002\end{array}$ & & & & \\
\hline II Neck Girth & $\begin{array}{l}0,170 \\
0,015\end{array}$ & $\begin{array}{l}0,138 \\
0,049\end{array}$ & & & \\
\hline II Bust Girth & $\begin{array}{l}0,115 \\
0,102\end{array}$ & $\begin{array}{l}0,190 \\
0,007\end{array}$ & $\begin{array}{l}0,330 \\
0,000\end{array}$ & & \\
\hline Waist Girth & $\begin{array}{l}0,076 \\
0,279\end{array}$ & $\begin{array}{l}0,270 \\
0,000\end{array}$ & $\begin{array}{l}0,230 \\
0,001\end{array}$ & $\begin{array}{l}0,481 \\
0,000\end{array}$ & \\
\hline Hip Girth & $\begin{array}{l}0,053 \\
0,451\end{array}$ & $\begin{array}{l}0,288 \\
0,000\end{array}$ & $\begin{array}{l}0,147 \\
0,036\end{array}$ & $\begin{array}{l}0,359 \\
0,000\end{array}$ & $\begin{array}{l}0,917 \\
0,000\end{array}$ \\
\hline
\end{tabular}

Results show that out of 203 females, the height of 96 could be classified as Short; 91 as Normal and 16 as Tall.

Table 2 clearly shows that the highest correlation holds between Hip Girth and Waist Girth ( $p$-value =0,000), followed by the Waist Girth and Bust Girth ( $p$-value $=0,000)$. Then comes the relation Bust Girth and Neck Girth (with $p$-value $=0,000$ ). Since all $p$-values are smaller to $<10-4$, there is sufficient evidence at $\alpha=10-4$ that the correlations are not zero.

The correlation value between Body Height and Bust Girth is 0,115 . This value shows a slight correlation between them and the $p$-value $=0.102$ shows that at $\alpha=0,102$ the correlation is not zero.

Figure 2 presents the scatter plot of Body height versus Bust Girth. Each of the pairs (Body Height, Bust Girth) is represented as a point plotted in two-dimensional coordinate system. Inspection of this scatter plot indicates that no simple curve will pass through all the points.

The relationship between the Waist and Hip Girth has been modeled using the regression equation (1). The statistics used to estimate this model are: $\mathrm{S}, \mathrm{R}-\mathrm{Sq}, \mathrm{R}-\mathrm{Sq}(\operatorname{adj})$. The regression equation is:

$$
\text { Hip Girth }=16,9122+1,04718 \text { Waist Girth }
$$

$$
S=9,18962 \quad R-S q=84,1 \% \quad R-S q(\operatorname{adj})=84,1 \%
$$

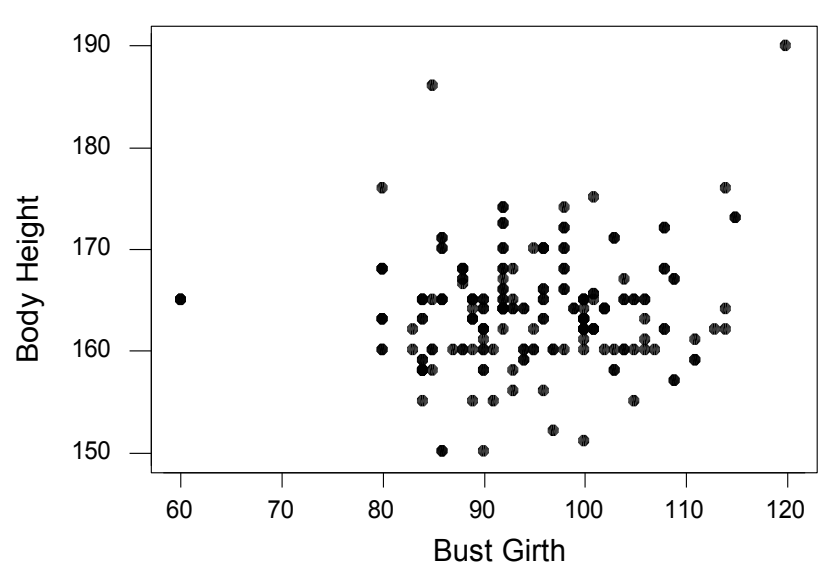

Figure 2. Body Height to the Bust Girth.

According to Table 5 results, model (1) presented above $(p$-value $=0,000)$ appears to provide a good fit to the data. The R-Squared indicates that only $84,1 \%$ of the variability in the Hip Girth is explained by the variable Waist Girth.

Comparing the EN 13402-1 standard for terminology, definitions and procedures for anthropometric measurements among 203 measured females can be laid.

(1) Bust and waist girths are the most important factors for the girth factor to identify the figure types. The derived parameter 
Table 5. Analysis of Variance.

\begin{tabular}{|c|c|c|c|c|c|}
\hline Source & DF & SS & MS & F & P \\
\hline Regression & 1 & 899 & 89996,5 & 1065,69 & 0,000 \\
\hline Error & 201 & 16974 & 84,4 & & \\
\hline Total & 202 & 106971 & & & \\
\hline
\end{tabular}

Table 6. Figure types identified on Bust Girth.

\begin{tabular}{|c|c|c|c|c|c|c|c|c|c|c|c|c|c|c|c|c|}
\hline Bust Girth & 76 & 80 & 84 & 88 & 92 & 96 & 100 & 104 & 110 & 116 & 122 & 128 & 134 & 140 & 146 & 152 \\
\hline EN STANDARD Range & $\begin{array}{c}74- \\
78\end{array}$ & $\begin{array}{c}78- \\
82\end{array}$ & $\begin{array}{c}82- \\
86\end{array}$ & $\begin{array}{c}86- \\
90\end{array}$ & $\begin{array}{c}90- \\
94\end{array}$ & $\begin{array}{c}94- \\
98\end{array}$ & $\begin{array}{c}98- \\
102\end{array}$ & $\begin{array}{c}102- \\
107\end{array}$ & $\begin{array}{c}107- \\
113\end{array}$ & $\begin{array}{c}113- \\
119\end{array}$ & $\begin{array}{c}119- \\
125\end{array}$ & $\begin{array}{c}125- \\
131\end{array}$ & $\begin{array}{c}131- \\
137\end{array}$ & $\begin{array}{c}137- \\
143\end{array}$ & $\begin{array}{c}143- \\
149\end{array}$ & $\begin{array}{c}149- \\
155\end{array}$ \\
\hline results & 6 & 8 & 27 & 30 & 31 & 29 & 40 & 8 & 15 & 3 & 6 & - & - & - & - & - \\
\hline
\end{tabular}

bust-to-waist ratio was measured to identify the figure types. The B/W factor was calculated for every woman from the overall group of 203 females. The ratio ranged between 0.9 and 1.5 , but concentrated between 1.1 and 1.3. The percentage of the other ratios came out to be less than $1 \%$, which means high cost for the industry production. So, it was excluded from the categorization of the female figure type according $\mathrm{B} / \mathrm{W}$ factor.

\section{Identification of the female figure through body shapes}

Main body shapes according the literature are:

1. Hourglass shape: Ratios bust - to - waist and waist - to hip are about equal

2. Bottom hourglass shape: This is a subcategory of the Hourglass shape with the same body measurements: bust, hip and waist. The criteria are: Waist circumference is larger than bust AND that ration bust - to - waist and waist - to hip are significant enough to produce a waistline.

3. Top hourglass shape: Larger bust circumference than hip AND that bust-to-waist and waist-to-hip ratios are significant to produce e definite waistline.

4. Rectangle shape: Bust and hip circumferences are more or less equal AND bust-to-waist and hip-to-waist are low.

5. Apple: The stomach region is wider than the hip section, mainly in males. This was not considered in our study.

6. Pear or spoon or bell: The hip section is wider than the upper body, mainly in females

The distribution of the females in our study according the body shape is shown in Figure 4.

From all the measured females only 1 person falls in the category Apple - without a significant waist line and waist larger than the bust. Five persons also do not have a proper waist line but the bust, waist and hip circumferences are equal. Nine other females have larger bust circumference than the hip
Table 7. Identification of figure types based on the bust-to waist ratio.

\begin{tabular}{|c|c|c|c|}
\hline Figure Type & B/W ratio & Number & Percentage \\
\hline Small Bust & 1 & 9 & 0.044335 \\
\hline Medium Bust & 1.1 & 60 & 0.295567 \\
\hline Full Bust & 1.2 & 74 & 0.364532 \\
\hline Large Bust & 1.3 & 47 & 0.231527 \\
\hline XL Bust & 1.4 & 8 & 0.039409 \\
\hline XXL Bust & 1.5 & 1 & 0.004926 \\
\hline Very Small Bust & 0.9 & 4 & 0.019704 \\
\hline & & 203 & 1 \\
\hline
\end{tabular}

Table 8. Identification of figure types according the three categories of body height.

\begin{tabular}{|l|c|c|c|c|}
\hline & $\begin{array}{c}\text { B/W } \\
\text { ratio }\end{array}$ & Short & Normal & Tall \\
\hline Figure Type & & $\mathbf{1 5 6 - 1 6 3}$ & $\mathbf{1 6 4 - 1 7 1}$ & $\mathbf{1 7 2 - 1 7 9}$ \\
\hline Medium Bust & 1.1 & 33 & 22 & 5 \\
\hline Full Bust & 1.2 & 33 & 36 & 5 \\
\hline Large Bust & 1.3 & 25 & 22 & - \\
\hline
\end{tabular}

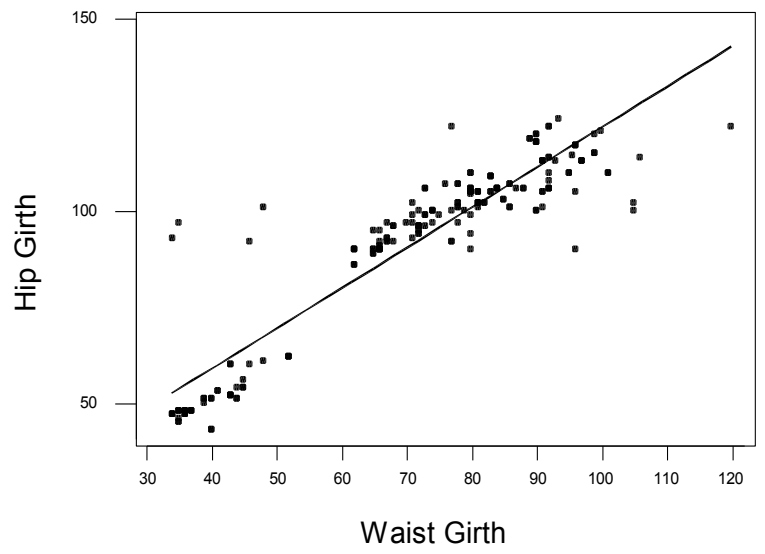

Figure 3. Scatter plot of Hip Girth to the Waist Girth and the regression curve. 


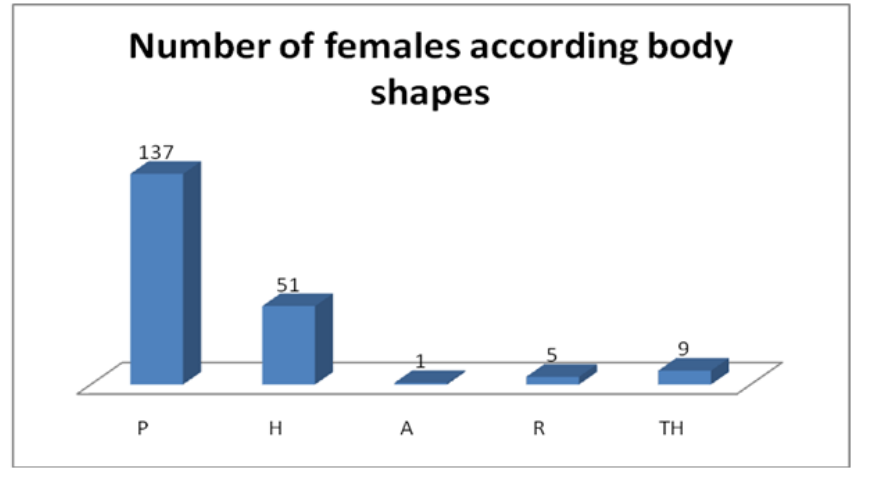

Figure 4. Distribution per body shape category.

circumference but a significant waist line. 56 females with Pear body shape are between 40 and 63 years old.

\section{Conclusions}

Body measurements standards are of a high importance for a successful apparel production. Without standards, mass production can be less accurate, efficient, less marketable and less profitable. The girth factor (B/W ratio) was used as an accurate parameter to classify figure types for developing an accurate industrial standard. On this basis, pattern makers can develop patterns with basic sizes. Body measurement systems used in the past have used girth differences to determine body types, which was not very effective. Few studies have applied girth ratio approach to body typing. In our study we applied the girth ratio for identifying four body types for our target consumers (bank employees), and developed body measurement standards for production. Results indicate that this proposed approach easily and accurately distinguishes between different body types. By applying the bust-to-waist ratio, four body types emerge. Sizes based on regular ratios within a given body type are to be taken into consideration from apparel manufacturers showing results in production. Manufacturers can make different types of apparel with various allowances, by referring to these accurate standards. Manufacturers may also refer to these standards to obtain detailed production information.

Regarding the second part of the study - body shape, it is the very first attempt to categorize the female structure into different body shapes. This is an ongoing project which will be supported and facilitated with the 3D Scanner, and the software that the Textile and Fashion department will soon have. Such studies will also help to better understand the changes and development of the body structure due to the changes in the socio-economic life, demographic, health and nutrition.

Production for small number of persons not necessarily requires developing a sizing system. This example served mainly to show the methodology how we are going to proceed for developing the national sizing system for mass production in industry level. The 203 persons (mainly females) has been considered 'sample'. The correct statistical representative sample will be selected according the proper statistical methodology for being representative of the whole population.

\section{Acknowledgments}

\section{References}

1. Simmons Karla et al, University of Missouri, Female Figure Identification Technique for Apparel

2. Alexander, M., Connell, L. J., \& Presley, A. B. (2005). Clothing fit preferences of young female adult consumers. International Journal of Clothing Science and Technology, 17, 52-64.

3. Ashdown, S. P. (1998). An investigation of the structure of sizing systems.

4. International Organization for Standardization (ISO). (1991). Standard sizing systems for clothes (technical report). ISO/TR10652, 19-25.

5. http://en.wikipedia.org/wiki/Anthropometry

6. William navidi. (2006). Probabilita e statistica per l' ingegneria e le scenze. Mc Graw-Hill.

7. Chin - Hung Hsu (2009), Human Factors and Ergonomics in Manufacturing and Service Industries, Volume 19, Issue 3, http://onlinelibrary.wiley.com/doi/10.1002/hfm.20148/ $p d f$ 